\title{
REVIEW
}

\section{Crop Development with Data-driven Approach towards Sustainable Agriculture: Lifting the Achievements and Opportunities of Collaborative Research between CIAT and Japan}

\author{
Satoshi OGAWA ${ }^{1}$, Michael Gomez SELVARAJ ${ }^{2}$ and Manabu ISHITANI ${ }^{2,3 *}$ \\ ${ }^{1}$ Crop, Livestock and Environment Division, Japan International Research Center for Agricultural \\ Sciences, Tsukuba, Japan \\ ${ }^{2}$ Crops for Nutrition and Health, Americas Hub, The Alliance of Bioversity International and CIAT, \\ Cali, Colombia \\ ${ }^{3}$ Crops for Nutrition and Health, Asia Regional Hub, The Alliance of Bioversity International and \\ CIAT, Hanoi, Vietnam
}

\begin{abstract}
International Center for Tropical Agriculture (CIAT) has a long history of collaboration with Japanese institutions to develop improved crop varieties and adopt agricultural technologies with pioneering approaches for farmers' benefit. Since 1972, Japan has enjoyed a long history of successful cooperation with the CGIAR (formerly the Consultative Group on International Agricultural Research) after becoming its 22nd Member to meet global challenges such as climate change affecting agriculture and food systems in diplomacy through Japan's advanced science and technology. This long-standing collaboration adopts agricultural technologies developed in Japan and promotes agricultural innovation through cutting-edge technologies such as remote sensing for Internet of Things (IoT) and Artificial Intelligence (AI) that will provide novel solutions to the agriculture and food sectors in the tropics. Nowadays, it is presumed that this approach to data-driven agriculture realization will help establish a sustainable agroecosystem with increased agricultural productivity and sustainability by adapting or mitigating the effects of climate change and efficient use of natural resources and establishing a sustainable food value chain. This review highlights the research collaborations and new opportunities on advanced breeding technologies and digital innovations towards data-driven agriculture. In conjunction, we present a potential collaborative research between CIAT and Japan, prioritizing the current and future challenges in agriculture and food systems.
\end{abstract}

Discipline: Crop Science

Additional key words: rice, cassava, tropical forage, Artificial Intelligence (AI), genome editing, marker-assisted breeding, precision agriculture

\section{Introduction}

International Center for Tropical Agriculture (CIAT, by its Spanish acronym) was established in 1967 with a mission of delivering research-based solutions to reduce hunger and poverty, increase the eco-efficiency of agriculture, and improve human nutrition and health in the tropics (Lynam \& Beyerlee 2017). In 2018, CIAT reformed its forces with an independent CGIAR Research Center to establish the Alliance of Bioversity International and CIAT. Since 1972, CIAT and Japan have continued their research collaborations for agricultural development. Until now, Japan has sent 37 staff consisting of 29 researchers, and three project administrators, to CIAT as internationally recruited or outposted staff in various research areas over different periods, in addition five board members contributed to strategic direction for delivering accountable performance in a mission: alleviation of hunger and poverty (Fig. 1). In 1977, Tropical Agriculture Research Center (TARC) was one of the first Japanese 
(A)

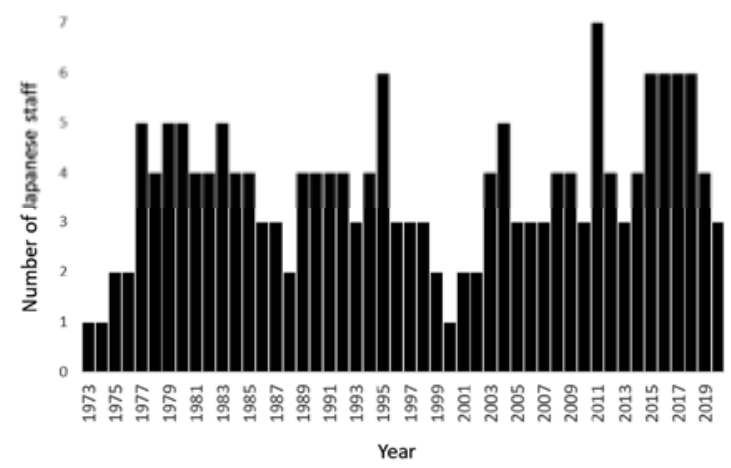

(B)

\begin{tabular}{|l|c|c|}
\hline \multicolumn{1}{|c|}{ Assinged Work Area } & Number of People & Note \\
\hline Board member & 5 & \\
\hline Program director & 1 & \\
\hline Breeding & 10 & 4 females included \\
\hline Agronomy & 13 & \\
\hline Resource management (e.8, soll, water) & 3 & \\
\hline Post-harvest & 0 & \\
\hline Livestock & 0 & \\
\hline Agro-forestry & 0 & \\
\hline Fisheries & 0 & \\
\hline Social sciences (e.g. economics, gender) & 1 & 1 female included \\
\hline Technology transfer & 0 & \\
\hline Project coordination & 3 & 1 female included \\
\hline Other & 1 & \\
\hline Total & 37 & \\
\hline
\end{tabular}

Fig. 1. Number of Japanese staff worked at CIAT and their assigned research area

(A) Bar graph shows the number of Japanese staff, including scientists, board members, and project administrative staff worked at CIAT for at least six months from 1973 to 2020. (B) The table shows the respective area of their job assignment, including board membership and project coordination. The female staff number is indicated in Note.

institutions to initiate exchanging the researchers to improve native grass pasture. Until 1993, eight researchers and three board members from TARC have been outposted in CIAT. Later, TARC was reorganized as Japan International Research Center for Agricultural Sciences (JIRCAS) and laid a foundation for a new collaborative project with CIAT's Rice Program to elucidate the physiological mechanisms controlling the adaptation of upland rice to acid and infertile savanna soils. Furthermore, the continuous collaborative research between CIAT and JIRCAS on the pasture has provided the first-time direct evidence of the biological nitrification inhibition (BNI), which showed inhibition of soil nitrification by plant root exudation (Subbarao et al. 2009). This phenomenon is considered as a genetic mitigation strategy to tackle GHG emissions in agriculture. (Subbarao et al. 2009, Karwat et al. 2017, Subbarao et al. 2017, Villegas et al. 2020).

Technological innovation and human capital development are the two important key aspects of research and development. In conjunction, aligning mindful research through partnerships will promote opportunities and equitable growth through agriculture. With that in mind, Ministry of Agriculture, Forestry, and Fisheries (MAFF) of Japan launched the JAPAN-CGIAR fellowship program in 2004. Through this, JIRCAS managed to send 19 short-term interns, especially university students, to train in biotechnology and field phenotyping from 2004 to 2013 at CIAT.

In 2007 , to improve the resilience of crop production against extreme weather events such as prolonged drought conditions, RIKEN and JIRCAS, supported by the MAFF of Japan, implemented two multi-institutional projects, namely; Dehydration-Response Element-Binding protein (DREB) and Genetically Modified (GM) Drought Tolerance in collaboration with CIAT, International
Maize and Wheat Improvement Center (CIMMYT), and International Rice Research Institute (IRRI), for 11 years (Nakashima \& Suenaga 2017, Nakashima \& Urao, 2020). In 2013, CIAT started to collaborate with the University of Tokyo and the other universities through Science and Technology Research Partnership for Sustainable Development (SATREPS) funded by Japan International Cooperation Agency (JICA) and the Japan Science and Technology Agency (JST) for a project entitled "Development and Adoption of Latin American Low-input Rice production system through Genetic Improvement and Advanced field management technology" (https://www. jst.go.jp/global/english/kadai/h2505_colombia.html). The project's initiative focuses on technology and knowledge transfer, with a broad objective to support smallholder Colombian rice farmers in making genetic improvements in yield. Japan provided technical expertise on markerassisted breeding, crop management, community-based precision agriculture, and horizontal technology transfer by sending two JICA coordinators, one long-term and 17 short-term experts from the University of Tokyo, Kyushu University, Tokyo University of Agriculture and Technology (TUAT), and National Agriculture and Food Research Organization (NARO) to CIAT and the National Federation of Rice Growers of Colombia (FEDEARROZ), University of Valle, Cali, Colombia.

After 2016, CIAT accepted three university students to help young Japanese gain practical molecular breeding and phenotyping experiences as part of Japan's PublicPrivate Partnership Student Study Abroad Program.

This review summarized the research achievements in crop development with data-driven approach through Japan's partnership projects over the past ten years, as shown in Table 1. With the main focus on rice as described above and CIAT's other mandate crops, such as cassava 
Table 1. Japan-funded projects from 2013 to present

\begin{tabular}{|c|c|c|}
\hline Project name and donor & CIAT program & Year \\
\hline $\begin{array}{l}\text { Development of drought-tolerant crops for developing countries } \\
\text { (Commissioned by JIRCAS) }\end{array}$ & Rice & FY2013 - FY2017 \\
\hline $\begin{array}{l}\text { SATREPS: Development and adoption of Latin American low- } \\
\text { input rice production system through genetic improvement and } \\
\text { advanced field-management technologies (JICA/JST) }\end{array}$ & Rice & FY2013 - FY2018 \\
\hline $\begin{array}{l}\text { On-the-Job research capacity building for food Security and } \\
\text { environmental conservation in developing countries (managed by } \\
\text { UNU, supported by MAFF) }\end{array}$ & Cassava & FY2014 - FY2016 \\
\hline $\begin{array}{l}\text { Environmental protection using traits associated } \\
\text { with biological nitrification inhibition (MAFF) }\end{array}$ & Tropical Forages & FY2014 - FY2017 \\
\hline $\begin{array}{l}\text { Quantifying the BNI-residual effect from B. humidicola on N- } \\
\text { recovery and N-use efficiency (NUE) of the subsequent annual } \\
\text { crops (Commissioned by JIRCAS) }\end{array}$ & Tropical Forages & FY2015 - present \\
\hline $\begin{array}{l}\text { SATREPS: Development and dissemination of sustainable } \\
\text { production system based on invasive pest management of cassava } \\
\text { in Vietnam, Cambodia, and Thailand (JST/JICA) }\end{array}$ & Cassava & FY2015 - present \\
\hline $\begin{array}{l}\text { Sustainable production of cassava in ASEAN countries by } \\
\text { development and adaptation of pest and disease management } \\
\text { (MOFA) }\end{array}$ & Cassava & FY2016 \\
\hline $\begin{array}{l}\text { Provision of seeds and capacity building for advanced agricultural } \\
\text { technology (beans) (MOFA) }\end{array}$ & Beans & FY2016 \\
\hline $\begin{array}{l}\text { Establishment of international research network led (hosted) by } \\
\text { Japan for the most advanced genome editing research in crops } \\
\text { (JSPS) }\end{array}$ & Rice and Cassava & FY2016 - FY2018 \\
\hline $\begin{array}{l}\text { Sustainable production of cassava in Asia by development and } \\
\text { adaptation of pest and disease management in the region (MOFA) }\end{array}$ & Cassava & FY2017 - FY2019 \\
\hline $\begin{array}{l}\text { Demonstrative research on agricultural IoT Platforms (contracted } \\
\text { by SoftBank, supported by MIC) }\end{array}$ & Rice & FY2018 - present \\
\hline $\begin{array}{l}\text { Development of cultivation management system to reduce } \\
\text { greenhouse gas derived from agriculture and its crop development } \\
\text { (MAFF) }\end{array}$ & Tropical forage and rice & FY2018 - present \\
\hline $\begin{array}{l}\text { Realization of three-way satisfaction in cassava industry by } \\
\text { developing and implementing prediction app using artificial } \\
\text { intelligence (MOFA) }\end{array}$ & Cassava & FY2020 - present \\
\hline
\end{tabular}

and tropical forages. In conjunction, we also outlined the strategic objectives of strengthening the partnership with Japan to achieve sustainable agriculture and food security to eradicate hunger in the rural areas.

\section{Rice crop development}

Since 2007, MAFF of Japan has supported two rice projects, namely DREB (FY2007-FY2012) and Genetically Modified (GM) Drought Tolerance (FY2013FY2017), funded over the 11 years as outlined in the previous section. To improve the grain yield and agronomic performance of rice in drought conditions, through a transgenic approach, we introduced 23 gene constructs in different combinations of drought-tolerant genes and promoters into an upland rice cultivar, Curinga (Nakashima \& Suenaga 2017, Nakashima \& Urao, 2020) (Fig 2). The transgenic lines were evaluated in the automated rainout-shelter-based upland drought screening protocols for Colombia's drought-affected areas (Selvaraj et al. 2017a, Selvaraj et al. 2017b).

We identified two promising genes: an Arabidopsis 
(A)

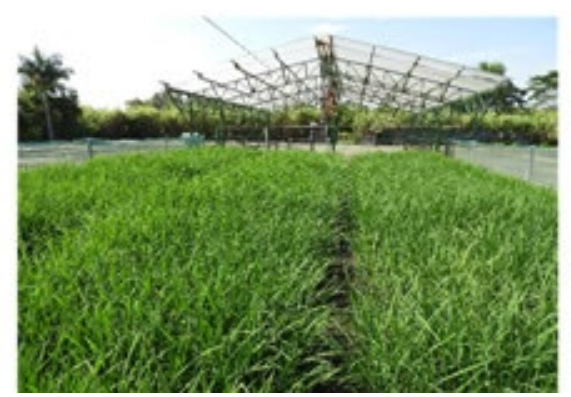

(B)

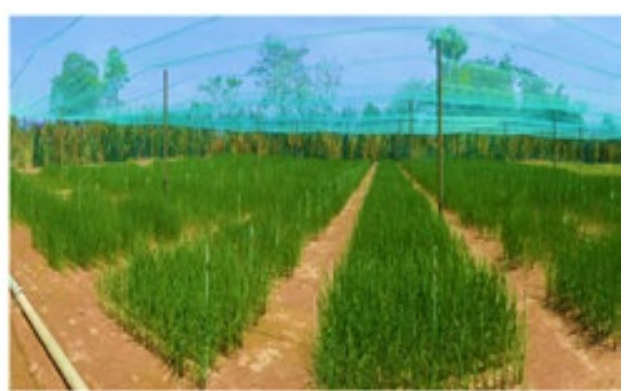

Fig. 2. Establishment of field screening platform for drought tolerance

(A) Drought screening facility under rainout shelter with boom irrigation system at CIATHQ. This facility can create a different degree of soil moisture level simultaneously by the boom system. (B) Drought tolerant evaluation of transgenic rice plants under rainfed actual field conditions, Santa Rosa, a drought-prone area in Meta Department, Colombia. Soil moisture sensors (AquaPro Sensors Inc. USA) were used to monitor soil moisture over the dry season from planting to harvest.

thaliana galactinol synthase (AtGolS2) with a constitutive promoter and rice $\mathrm{CCCH}$-tandem zinc finger protein gene (OsTZF5) with the stress-inducible promoter for increased grain yield in Curinga transgenic lines (Selvaraj et al. 2017a, Selvaraj et al. 2020a). These underline CIAT's successful accomplishments of desired results in confined field drought stress experiments involving Japanese institutions, made CIAT a hub for GM crop evaluation. This CIAT's expertise offers a unique place towards establishing the GM research platform, handle and evaluate GM crops' compliance with national and international biosafety regulations issued by the Colombian Agricultural Institute (ICA, by its Spanish acronym), the equivalent of USDA that does not require an event-by-event permit.

CIAT has contributed to establishment of several root phenotyping methods, including evaluating the effect of deeper rooting gene (DROI) in the field, hydroponics methods, and non-destructive detection methods; phenotowers and unmanned aerial vehicles (UAVs). Through the drought phenotyping methods established at CIAT's phenotyping platform, we evaluated the effect of DRO1 on yield performance in response to different levels of drought stress (none, mild and severe) using the automated rainout shelter with boom irrigation system (Uga et al. 2013a). This result indicates deeper rooting trait helps improve drought tolerance in rice. Through markerassisted breeding, five different root QTLs (DRO1, DRO2, DRO3, qRL6.1, qFSR4) (Uga et al. 2013a, Uga et al. 2013b, Obara et al. 2010 and Uga et al. 2015) were introgressed in Colombian rice varieties. Among the $\mathrm{BC}_{3} \mathrm{~F}_{5}$ lines tested, two promising lines with a different set of QTLs were identified as better agronomical performers than controls. The lines are being tested in multi-location trials of rice-growing areas for variety registration by
FEDEARROZ (data not shown). Furthermore, to extend our root research in rice, we established a hydroponic root evaluation system under greenhouse conditions at CIAT, which showed the usefulness of evaluating rooting pattern with different nutrient concentrations, especially $\mathrm{NH}_{4}{ }^{+}, \mathrm{NO}_{3}{ }^{-}$and phosphorus (Uga et al. 2013a, Ogawa et al. 2014a, Ogawa et al. 2014b).

Since 2010, there has been increased interest in lowcost, high-throughput phenotyping platforms to accelerate breeding programs (Pereyra-Irujo et al. 2012). In CIAT, we focus on developing advanced techniques, including realtime field monitoring and non-destructive measurement, which provide breeders, agronomists, and producers with precise information on crops and environments for data-driven agriculture. Along with the success story of the DRO1 gene, in collaboration with NARO of Japan, the SATREPS rice project was launched in 2013 and adapted hyperspectral and multispectral remote sensing technology for the first time at CIAT. Remote sensing images taken from UAVs or cameras placed on eightmeter-high pheno-towers analyzed by image processing software successfully estimated yield-related traits, especially grain weight, shoot biomass, and panicle number under different soil-nitrogen fertility (Naito et al. 2017) and drought conditions (Shimojima et al. 2017). The resulting data provided scientists with phenology of plants under the given conditions. This is particularly important to select water- or nitrogen-use efficient crop variety in breeding process under different cultivation environments for improved crop productivity.

\section{Cassava crop development}

CIAT has significantly impacted cassava improvement 
and development in Asia, with its national research partners, over the last 50 years, where cassava is an essential food and cash crop (Malik et al. 2020). In 1972, the Cassava Program started building an extensive collection of germplasm and formed a multi-disciplinary team of researchers to support basic and applied research. Later in 1983, CIAT got a core collection of cassava germplasm to start a cassava conventional breeding program in Thailand led by Dr. Kazuo Kawano, cassava breeder, CIAT. However, the heterozygous genetic makeup of the crop makes cassava breeding challenging. However, KU50, one of the important variety in South East Asia (SEA), was developed and officially released in Thailand in 1993 and is still recognized as the farmer-preferred variety in the cassava belt: Thailand, Cambodia, and Vietnam (Ceballos et al. 2004, Kawano et al. 1978, Kawano 2003, Kawano 2011). After the national cassava breeding platform was established in Thailand, our efforts on breeding extended to neighboring countries, and in parallel, our research's focus shifted to improve the agronomic practices in cassava farming, such as weed control and soil erosion (Malik et al. 2020). As a result, average cassava yield has been doubled since CIAT started working in SEA (Kawano 2003). This was made possible through the continuous efforts and commitments through the cassava sectors in the region and the long-term financial support from the Nippon Foundation.

In recent days, cassava sectors in SEA seek new varieties with better agronomic and value-added traits to meet the demands of starch and food markets (Toae et al. 2019). Thus, to meet the local needs, CIAT established International Laboratory for Cassava Molecular Breeding (ILCMB) in 2012 in collaboration with Agricultural Genetics Institute (AGI) and RIKEN to facilitate cassava breeding in Asia (Malik et al. 2020). The objectives of the ILCMB are to 1) establish a seed system to facilitate the adaptation of new variety, and 2) speed up variety development using new breeding techniques (NBT), such as genome editing, and 3) human capital development through establishing practical knowledge and technology transfer developed at CIAT-HQ in Colombia and elsewhere. Through the ILCMB, RIKEN contributed to bringing new molecular insights of cassava flowering by transcriptome analysis (Tokunaga et al. 2020) and building capacity to deliver improved cassava varieties through molecular breeding approaches.

Genome editing is a potential game-changer in crop breeding, defined as a collection of advanced molecular biology techniques that facilitate precision breeding where conventional breeding still plays a key role in variety development (Hsu et al. 2014, Zhang et al. 2018). To establish genome-editing techniques in commercial cassava cultivars in SEA, CIAT collaborated with the Japan Society for the Promotion of Science (JSPS) (20162018) to establish an international research network that helps promote precise genome editing research in crops including rice and cassava. This project aimed to transform and develop the genome editing technology for the most popular variety, KU50, with the collective efforts of an expert team from Yokohama City University, NARO, RIKEN, Purdue University, and the University of Minnesota. In this project, we improved the efficiency of the friable embryogenic callus (FEC) induction which is the vital step (Utsumi et al. 2017) in Agrobacteriummediated transformation that helps introduce desired mutations in the current CRISPR-Cas9 system (Zhang et al. 2018).

More recently, invasive new cassava pests and diseases such as Sri Lankan cassava mosaic virus (SLCMV) have become a serious threat to cassava sectors (Minato et al. 2019). After the first report of the SLCMV in Cambodia (Wang et al. 2016), the disease quickly spread in neighboring countries despite all the quarantine measures. It is mainly due to the lack of clean seed and disease monitoring systems within and across the borders. Hence, the SATREPS program launched a five-year phased multi-country project in 2015 for the "Development and Dissemination of Sustainable Production System based on Invasive Pest Management of Cassava in Vietnam, Cambodia, and Thailand" (https://www.jst.go.jp/global/ english/kadai/h2708_vietnam.html). This project involves Japan's Kyushu University as a lead and other counterpart institutions of Japan and related countries. CIAT's role is to select and transfer cassava germplasm with a known source of resistance to SLCMV from its HQ to the projectassociated countries (Minato et al. 2019).

Besides this, an efficient pest and disease management protocol involves mapping the locations of SLCMVinfected and clean planting material producers to prevent the further spread of the disease before the start of the new planting season. Through CIAT Pheno-i platform (https:// ciat.cgiar.org/phenomics-platform/phenoi/) which consists of remote sensing and data analysis pipeline with machine learning algorithms to analyze and validate a large set of ground truth and image data and predict the targeted traits (Selvaraj et al. 2020b), CIAT explores the opportunities to integrate the above ground (aerial) and below ground (Ground Penetrating Radar) information to predict the root yield, which can be applied to the SATREPS project as well. Besides, we are also developing a smartphonebased mobile app using Pheno-i platform with more than 10,000 symptomatic photos of the SLCMV disease taken in Vietnam, which can be tagged with the GPS location to identify the disease quickly. One such example is the 
banana AI app (Tumaini) launched in 2019 to detect early signs of banana diseases (Selvaraj et al. 2019). Once the project ends, JICA will direct the counterpart institutions in the target countries to monitor the dissemination of research outputs with key performance indicators to assess impact.

\section{Tropical forage crop development}

An excellent example of scientific achievements between Japan and CIAT is the identification of a new biological phenomenon called "Biological Nitrification Inhibition (BNI)," a trait that was first discovered in a tropical forage, Brachiaria humidicola, and has the potential to reduce greenhouse gas (GHG) emissions (Subarrao et al. 2009, Subarrao et al. 2017). A longstanding partnership between JIRCAS and CIAT has grown stronger over the years through BNI research, which promoted our understanding of applying this phenomenon in agricultural systems (Subarrao et al. 2009). This collaboration revealed that a significant residual BNI effect from Brachiaria humidicola prevented re-mineralized $\mathrm{N}$ from nitrification, resulting in improved maize performance (Karwat et al. 2017). We could also select Brachiaria humidicola hybrids with high BNI effects for sustainable livestock production in the future (Nuñez et al. 2018). Furthermore, through the leadership of JIRCAS, we can extend this BNI phenomenon to other grain crops such as sorghum, rice, maize, and wheat (Coskun et al. 2017). One such measure is establishing the
BNI International Consortium (https://www.jircas.go.jp/ en/program/program_a/bni) to understand the genetic and biochemical mitigation of GHG emissions through BNI phenomenon in farming systems (Subarrao et al. 2017).

For the phenotyping of improved tropical forages including BNI traits, we should consider integrated agropasture system with grassland and cattle management in daily operations to attract the livestock sector (Shalloo et al. 2018). Towards the goal of optimal grazing management, a project supported by MAFF of Japan is developing an AI-based model integrating the UAV and satellite images of the grazing cycle to use as a decision support system (Insua et al. 2019). The preliminary result indicates that vegetation indices were significant in identifying grass growth rates before- and- after grazing in the rotation scheme (Fig. 3). We envision integrating the yet-to-bedeveloped model into an automated mobile app, such that cattle producers will be able to make better decisions to improve livestock productivity with less environmental footprint and reduce daily workload. Furthermore, this mobile application may pave the way to build a digital livestock value chain by integrating other values such as animal health and traceability of animal production (Shalloo et al. 2018).

\section{Data-driven agriculture}

Despite the incredible advances in crop breeding, until now, our ability to monitor crop status in the field was very limited due to the lack of technological and analytical

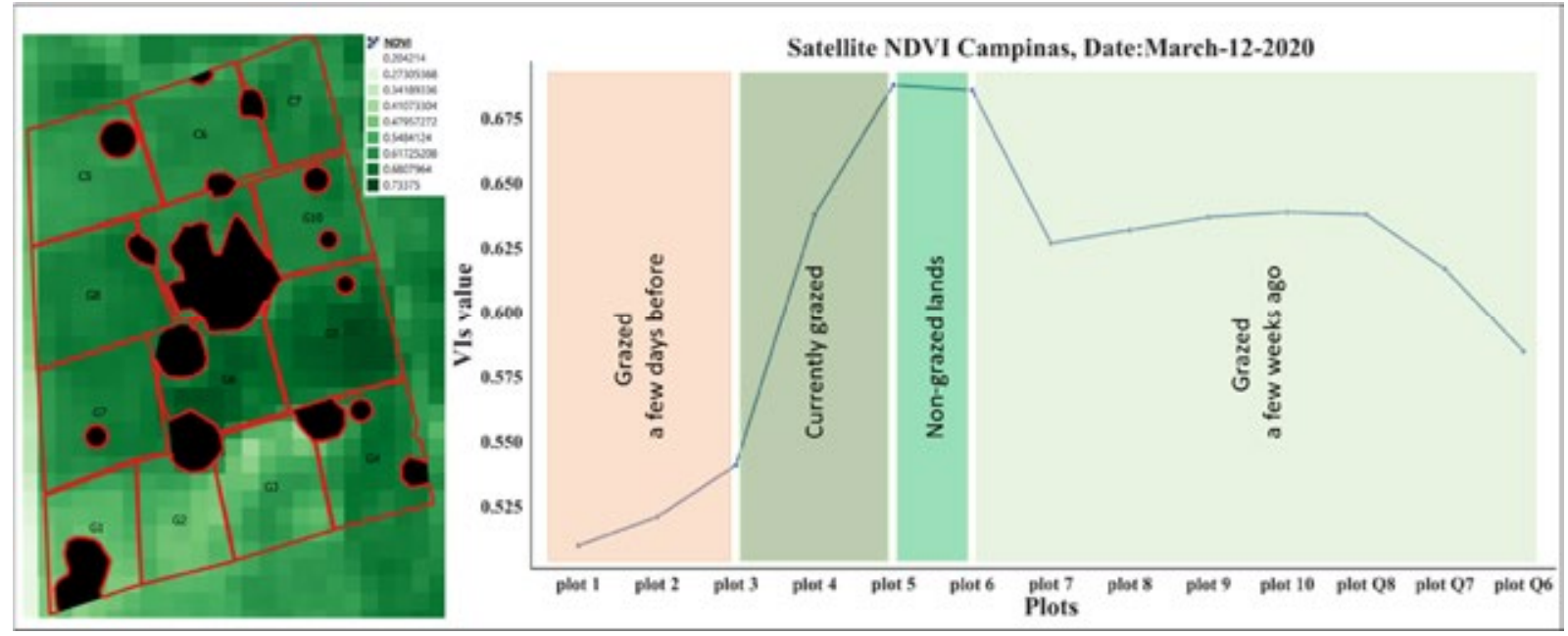

Fig. 3. Sentinel 2 based NDVI map and growth trend of grazing plots at one experimental farm of Cauca Department, Colombia

Every 5-7 days, a group of cattle is rotated in 13 plots of grazing lands in the farm (Left: NDVI image with plots). To improve animal productivity and minimize environmental impacts by overgrazing, forage biomass is measured by Normalized Difference Vegetation Index (NDVI) derived from Sentinel 2 images. The preliminary result indicates the growth trend of NDVI matches with the current rotation cycle, which will be further confirmed with ground truth and UAV image data. 
tools (Jung et al. 2020). However, recent advances in crop mapping and monitoring using remote sensing (typically from smartphones, drones, and satellites) and AI with large data storage capabilities are making a substantial impact on the research community and transform the ways to manage the real-time practices for improved agricultural productivity and sustainability (Araus et al. 2018, Tattaris et al. 2016). Towards the data-driven agriculture, CIAT recently developed Pheno-i (https://ciat. cgiar.org/phenomics-platform/phenoi/), an image analysis platform as described above. At present, this platform is being tested and upgraded for the analytical capacity to keep pace with the progress of this research field in various research projects such as the described cassava and tropical forage projects in Table 1.

Through the SATREPS rice project, an IoT agricultural solution, named as e-kakashi, provided by Softbank Corp., Japan was introduced to CIAT for precise environmental monitoring and predicting crop phenological status under field conditions, which will help farmers to make better decisions on crop management, such as harvesting time and disease control. This unit collects real-time field environmental data such as temperature, solar radiation, and carbon dioxide concentration through sensor nodes installed at the target field sites. Furthermore, IoT tools' unique feature is the AI analytics-based machine learning algorithms to discover insights and relationships in realtime or large data sets. At CIAT, we tested the usefulness of e-kakashi to predict the important growth stages of rice from 14,000 meteorological, phenological, and agronomical data of Colombian rice varieties collected over the period of four years from 2013 to 2017. The preliminary data suggest that e-kakashi AI analysis can estimate different growth stages of rice, such as heading and flowering time, within a maximum of two days difference in the tested two Latin-American rice varieties (Fig. 4). With the support of the Inter-American Development Bank (IDB)-Lab, we are testing the IoT agricultural solution in farmer's fields to understand the applicability and bottlenecks in its use towards data-driven agriculture under different economic and environmental conditions of Colombia.

\section{New opportunities}

In line with Japan's strategic objectives of inclusive and dynamic development in agriculture and CIAT's global expertise and partnerships to reduce poverty through sustainable agriculture, we can help find innovative solutions to major global challenges (e.g., COVID-19 pandemic) now and in the decades to come.

The two most impactful research areas in agriculture will be of mutual interest among other potential areas to strengthen the research collaboration between CIAT and Japan. One area is developing and deploying genomeediting technology to produce better crops to improve human health and nutrition and income generation. For instance, recently, Japan approved the first genome-edited tomato with increased gamma-aminobutyric acid (GABA) for commercialization (Gramazio et al. 2020). In the same line of the story, the Colombian regulator (ICA) classified 20 genome-edited rice varieties that have been tested in CIAT's confined field trials as equivalent to conventional varieties in 2020 (Fernando et al. 2020). These genetically edited rice varieties resistant to bacterial blight, caused by Xanthomonas oryzae, are also being evaluated in multilocation field trials to confirm the agronomic performance
(A)

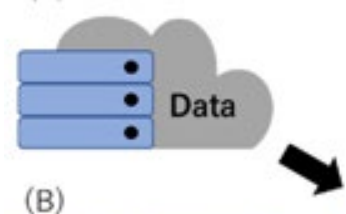

(B)

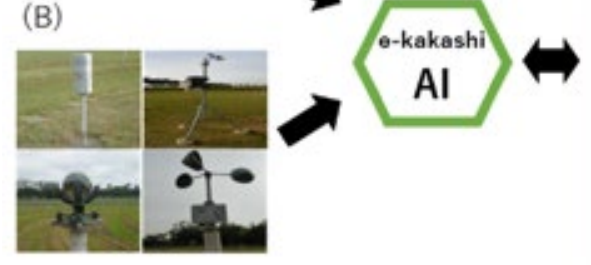

(D)
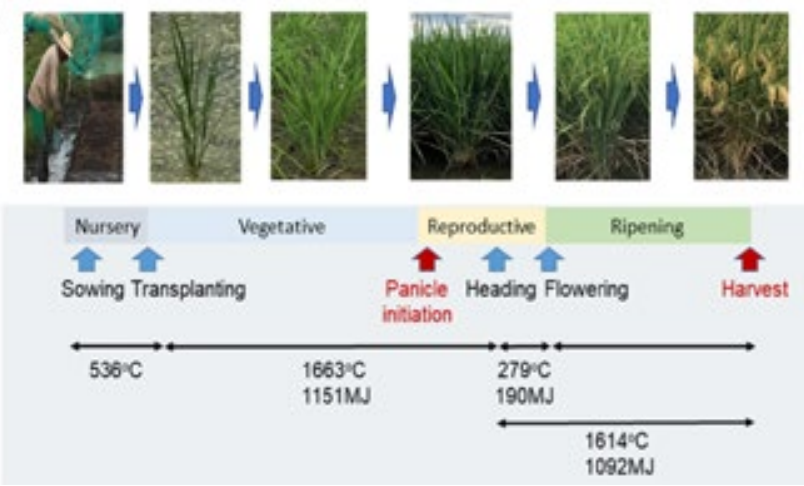

Fig. 4. A schematic view of predicting rice phenological stages using agronomical and meteorological data (A) The phenological and agronomical datasets on a server collected under lowland field conditions in CIAT-HQ from 2013 to 2017. At the same sites, various meteorological equipment was used to collect the environmental data such as air temperature, light intensity, and rainfall (B). Fourteen thousand data points, including phenological, agronomical, and meteorological data, were analyzed in e-kakashiequipped AI analytics (C) to predict plants' phenological stages (D). The phenological stage diagram shows the accumulated air temperature $\left({ }^{\circ} \mathrm{C}\right)$ and light intensity (MJ: mega joule) predicting the flowering period. 
(Oliva et al. 2019). With the technical expertise and policy support gained from both countries, we have a unique opportunity to deploy genome editing technology to facilitate Proof of Concept (POC) work in the countries where the technology is much needed.

Another research area is to develop and deploy digital technologies to create a data-driven food value chain from farm to table to reduce input supplies (e.g., water, chemical fertilizers) and food loss, contributing to Sustainable Development Goals (SDGs) (Nat Sustain 2020). For instance, the agriculture sector counts for $24 \%$ of global GHG emissions (IPCC 2014). The water-levelsensor to measure the exact level of irrigated water may reduce the unnecessary wastage of water by reducing methane emission from the paddy field while sustaining the agroecological farming (Chirinda et al. 2018). This may be applied to BNI technology to reduce the conversion of $\mathrm{N}$ fertilizers into $\mathrm{N}_{2} \mathrm{O}$ emissions from modern farming systems. However, the agriculture sector was not part of GHG trading schemes such as the carbon market recently due to inadequate measurement tools and uncertainty of benefits for the objective (Amelung et al. 2020).

Finally, digital innovation opens a door for private sectors to engage in agricultural business through the information and communication technology (ICT) (e.g., smartphone), to develop value (e.g., new market) by providing their proprietary service to agriculture sectors, including farmers in an affordable way (Ingram \& Maye 2020). Thus, establishing a reliable public-private sector partnership will help create three-way satisfaction for producers, buyers, and the community. There are many exciting research areas to strengthen scientific collaboration with Japanese institutions through donor support, including the Government of Japan with existing and future funding schemes. CIAT will be delighted to establish such partnerships through human capacity development involving young Japanese researchers.

\section{Conclusions}

For nearly half a century, we have witnessed the compelling achievements of research outputs and impacts on breeding and agronomy in CIAT mandate crops by integrating knowledge and advanced technologies through scientific collaborations with Japanese institutions. As we face new challenges globally in agriculture and food systems, our thinking and strategies showed dynamic ways to tackle these challenges through digital technologies and $\mathrm{AI}$ at a scale and speed.

In the data-driven agriculture era, we will continue to deploy advanced technologies to provide solutions to end-users on the ground to close the last mile of the gap between agriculture and the food system through strong partnerships with different stakeholders. It is important to consider the best selection of technologies suitable for agro-ecological farming to deliver a lasting impact. Finally, this can only be achieved through human capital development, which is inevitable for technological innovation and establishing reliable partnerships.

\section{Acknowledgment}

We would like to thank all the local research staff for generating the data presented in this manuscript. Also, we thank Angela Fernando for the critical editing of this manuscript. We would like to express sincere appreciation to Drs. Kazuo Shinozaki and Motoaki Seki of RIKEN, Drs. Yusaku Uga, Masaki Endo, and Seiichi Toki of NARO, Drs. Takashi Togami and Kyosuke Yamamoto of Softbank Corp., Profs. Kensuke Okada, Kazuko Shinozaki and Kenji Omasa of University of Tokyo, Drs. Sakae Shibusawa and Shinji Fukuda of Tokyo University of Agriculture and Technology, Drs. Keiji Takasu and Teruaki Nanseki of Kyushu University, Drs. Satoshi Tobita, Subbarao Guntur, Takeshi Urao, and Kazuo Nakashima of JIRCAS, Prof. Kiyoshi Honda of Chubu University to make it possible to deliver research outputs described in this manuscript among many other researchers. We also thank Drs. Joe Tohme, Luis Augusto Becerra Lopez-Lavalle, María Fernanda Álvarez, Michael Peters, Crops for Nutrition and Health research area of the Alliance Dr. Eduardo Graterol of Latin American Fund for irrigated Rice (FLAR, by its Spanish acronym) for their continuous support.

SATREPS rice and cassava projects were supported by Japan International Cooperation Agency (JICA) and Japan Science and Technology Agency (JST). Demonstrative research on agricultural IoT platform (e-kakashi) projects are supported by Inter-American Development Bank (IDB)-Lab and Ministry of Internal Affairs and Communications of Japan. Projects related to rice, tropical forage, cassava, and genome editing are supported by the Ministry of Agriculture, Forestry, and Fisheries (MAFF), Ministry of Foreign Affairs of Japan (MOFA), Nippon Foundation, and Japan Society for the Promotion of Science (JSPS), respectively.

\section{References}

Amelung, W. et al. (2020) Towards a global-scale soil climate mitigation strategy. Nat Commun., 11, 5427. DOI:10.1038/ s41467-020-18887-7.

Araus, J.L. et al. (2018) Translating high-throughput phenotyping into genetic gain. Trends Plant Sci., 23, 451-466.

Ceballos, H. et al. (2004) Cassava breeding: opportunities and 
challenges. Plant Mol. Biol., 56, 503-516.

Chirinda, N. et al. (2018) Sustainable and low greenhouse gas emitting rice production in Latin America and the Caribbean: A Review on the transition from ideality to reality. Sustainability, 10, 671. DOI: 10.3390/su10030671.

Coskun, D. et al. (2017) Nitrogen transformations in modern agriculture and the role of biological nitrification inhibition. Nature Plants, 3, 17074. DOI: 10.1038/nplants.2017.74.

Gramazio, P. et al. (2020) Challenges and prospects of new plant breeding techniques for GABA improvement in crops: Tomato as an Example. Front. Plant Sci., 11, 577980. DOI: $10.3389 /$ fpls.2020.577980.

Fernando, A. et al. (2021) Clearinghouse for Genome-Edited crops and field testing. Mol Plant., 14, 3-5.

Hsu, P.D. et al. (2014) Development and applications of CRISPR-Cas9 for genome engineering. Cell, 157, 1262-78.

Ingram, J. \& Maye, D. (2020) What Are the Implications of Digitalisation for Agricultural Knowledge? Front. Sustain. Food Syst., 4, 66. DOI: 10.3389/fsufs.2020.00066.

Insua, J.R. et al. (2019) Estimation of spatial and temporal variability of pasture growth and digestibility in grazing rotations coupling unmanned aerial vehicle (UAV) with crop simulation models. PLoS ONE, 14, e0212773. DOI: 10.1371/journal.pone.0212773.

IPCC (2014) Climate Change 2014: Synthesis Report. Contribution of Working Groups I, II and III to the Fifth Assessment Report of the Intergovernmental Panel on Climate Change [Core Writing Team, RK Pachauri and L.A. Meyer (eds.)]. IPCC, Geneva, Switzerland, 151.

Jung, J. et al. (2020) The potential of remote sensing and artificial intelligence as tools to improve the resilience of agriculture production systems. Curr Opin Biotechnol., 70, 15-22.

Karwat, H. et al. (2017) Residual effect of BNI by Brachiaria humidicola pasture on nitrogen recovery and grain yield of subsequent maize. Plant Soil, 420, 389-406.

Kawano, K. et al. (1978) Evaluation of cassava germplasm for productivity. Crop Sci., 18, 377-380.

Kawano, K. (2003) Thirty years of cassava breeding for productivity - biological and social factors for success. Crop Sci., 43, 1325-1335.

Kawano, K. (2011) The triumphant cassava chronicled by foresight, political will and accountability. J. Root Crops, 37, 101-110.

Lynam, J. \& Byerlee, D. (2017) Forever pioneers - CIAT: 50 years contributing to a sustainable food future... and counting. CIAT Publication. No. 444. International Center for Tropical Agriculture (CIAT), Cali, Colombia. 140. Available at: http://hdl.handle.net/10568/89043.

Malik, A.I. et al. (2020) Cassava breeding and agronomy in Asia: 50 years of history and future directions. Breeding Science, 70, 145-166.

Minato, N. et al. (2019) Surveillance for Sri Lankan cassava mosaic virus (SLCMV) in Cambodia and Vietnam one year after its initial detection in a single plantation in 2015. PLoS ONE, 14, e0212780. DOI: 10.1371/journal.pone.0212780

Naito, H. et al. (2017) Estimating rice yield related traits and quantitative trait loci analysis under different nitrogen treatments using a simple tower-based field phenotyping system with modified single-lens reflex cameras. ISPRS Journal of Photogrammetry and Remote Sensing, 125, 5062.
Nakashima, K. \& Suenaga, K. (2017) Toward the Genetic Improvement of Drought Tolerance in Crops, JARQ, 51, $1-10$.

Nakashima, K. \& Urao, T. (2020) Development of biotechnologies and biotech crops for stable food production under adverse environments and changing climate conditions. (Ed.) JIRCAS Working Report No. 91.

Nat. Sustain. (2020) Innovating the food value chain. Nat. Sustain., 3, 1. DOI: 10.1038/s41893-020-0471-3.

Nuñez, J. et al. (2018) Biological nitrification inhibition activity in a soil-grown biparental population of the forage grass, Brachiaria humidicola. Plant Soil, 426, 401-411.

Obara, M. et al. (2010) Fine-mapping of qRL6.1, a major QTL for root length of rice seedlings grown under a wide range of $\mathrm{NH}_{4}{ }^{+}$concentrations in hydroponic conditions, Theoretical and Applied Genetics, 121, 535-547.

Ogawa, S. et al. (2014a) Root system architecture variation in response to different $\mathrm{NH}_{4}{ }^{+}$concentrations and its association with nitrogen-deficient tolerance traits in rice. Acta Physiol Plant, 36, 2361-2372.

Ogawa, S. et al. (2014b) N and P mediated seminal root elongation response in rice seedlings. Plant Soil, 375, 305315.

Oliva, R. et al. (2019) Broad-spectrum resistance to bacterial blight in rice using genome editing. Nat. Biotechnol., 37, 1344-1350.

Pereyra-Irujo, G.A. et al. (2012) GlyPh: a low-cost platform for phenotyping plant growth and water use. Funct. Plant Biol., 39, 905-913.

Selvaraj, M.G. et al. (2017a) Overexpression of an Arabidopsis thaliana galactinol synthase gene improves drought tolerance in transgenic rice and increased grain yield in the field. Plant Biotechnol. J., 15, 1465-1477.

Selvaraj, M.G. et al. (2017b) Development and field performance of nitrogen use efficient rice lines for Africa. Plant Biotechnol. J., 15, 775-787.

Selvaraj, M.G. et al. (2019) AI-powered banana diseases and pest detection. Plant Methods,15, 92. DOI:10.1186/s13007019-0475-z.

Selvaraj, M.G. et al. (2020a) Expression of the CCCH - tandem zinc finger protein gene OsTZF5 under a stress - inducible promoter mitigates the effect of drought stress on rice grain yield under field conditions. Plant Biotechnology Journal, 18, 1711-1721.

Selvaraj, M.G. et al. (2020b) Machine learning for highthroughput field phenotyping and image processing provides insight into the association of above and below-ground traits in cassava (Manihot esculenta Crantz), Plant Methods, 16, 87. DOI: 10.1186/s13007-020-00625-1.

Shalloo, L. (2018) Review: Grass-based dairy systems, data and precision technologies. Animal, 12, S262-S271.

Shimojima, K. et al. (2017) Comparison between rice plant traits and color indices calculated from UAV remote sensing images. ECO-Engineering, 29, 11-16.

Subbarao, G.V. et al. (2009) Evidence for biological nitrification inhibition in Brachiaria pastures. Proc. Natl. Acad. Sci., 106, 17302-17307.

Subbarao, G.V. et al. (2017) Genetic mitigation strategies to tackle agricultural GHG emissions: the case for biological nitrification inhibition technology. Plant Sci., 262, 165-168.

Tattaris, M. et al. (2016) A direct comparison of remote sensing 
approaches for high-throughput phenotyping in plant breeding. Front. Plant Sci., 7, 1131. DOI: 10.3389/fpls.2016.01131.

Toae, R. et al. (2019) Outstanding characteristics of Thai NonGM Bred Waxy Cassava starches compared with normal cassava starch, Waxy Cereal Starches and Stabilized Cassava Starches. Plants, 8, 447. DOI: 10.3390/plants 8110447.

Tokunaga, H. et al. (2020) Field transcriptome analysis reveals a molecular mechanism for cassava-flowering in a mountainous environment in Southeast Asia. Plant Mol Biol. 2020 Sep 9. DOI: $10.1007 / \mathrm{s} 11103-020-01057-0$.

Uga, Y. et al. (2013a) Control of root system architecture by DEEPER ROOTING 1 increases rice yield under drought conditions. Nat. Genet., 45, 1097-1102.

Uga, Y. et al. (2013b) A major QTL controlling deep rooting on rice chromosome 4. Sci. Rep., 3, 3040. DOI: 10.1038/ srep03040.

Uga, Y. et al. (2015) A QTL for root growth angle on rice chromosome 7 is involved in the genetic pathway of
DEEPER ROOTING 1. Rice, 8. DOI: 10.1186/s12284-0150044-7.

Utsumi, Y. et al. (2017) Formation of friable embryogenic callus in cassava is enhanced under conditions of reduced nitrate, Potassium and Phosphate. PLoS ONE, 12, e0180736. DOI:10.1371/journal.pone.0180736.

Villegas, D. et al. (2020) Biological Nitrification Inhibition (BNI): Phenotyping of a core germplasm collection of the tropical forage grass Megathyrsus maximus under greenhouse conditions. Front. Plant Sci., 11, 820. DOI: $10.3389 /$ fpls.2020.00820.

Wang, H.L. et al. (2016) First report of Sri Lankan cassava mosaic virus infecting cassava in Cambodia. Plant Dis., 100, 1029-1029.

Zhang, Y. et al. (2018) Applications and potential of genome editing in crop improvement. Genome Biol., 19, 210. DOI: 10.1186/s13059-018-1586-y. 